\title{
ARTICLE
}

\section{Antisocial personality disorder: new directions}

\author{
Jessica Yakeley \& Andrew Williams
}

\begin{abstract}
Jessica Yakeley is a consultant psychiatrist in forensic psychotherapy at the Portman Clinic, and Director of Medical Education and Associate Medical Director at the Tavistock and Portman NHS Foundation Trust. She is the editor of Psychoanalytic Psychotherapy. The Portman Clinic specialises in the treatment of paraphilias, criminality, and violent and antisocial behaviour. Andrew Williams is a consultant psychiatrist in forensic psychotherapy at the Portman

Clinic, Tavistock and Portman NHS Foundation Trust. Both authors are leading on the national development of mentalisation-based treatment community services for offenders with a diagnosis of antisocial personality disorder as the clinical component of a planned multisite randomised controlled trial. The services will be jointly delivered by health service providers and the National Probation Service as an integrated part of the National Offender Personality Disorder

Pathway Strategy.

Correspondence Jessica Yakeley, Portman Clinic, 8 Fitzjohns Avenue, London NW3 5NA, UK. Email: jyakeley@tavi-port.nhs.uk
\end{abstract}

\begin{abstract}
SUMMARY
Antisocial personality disorder is a complex condition carrying high rates of comorbidity and mortality for individuals as well as harmful consequences for their families and society. Despite the publication of National Institute for Health and Care Excellence (NICE) guidelines for the disorder, the evidence base and provision of effective treatments remain inadequate, and the belief that the condition is untreatable remains widespread among psychiatrists and other professionals. This article highlights current diagnostic controversies and summarises the evidence for conceptualising antisocial personality disorder as a disorder of attachment. Informed by this developmental perspective, we provide a framework for the management and treatment of adults with antisocial personality disorder, highlighting the importance of creating a safe setting and recommending adaptations of therapeutic technique to facilitate the engagement of this 'treatment-rejecting' patient population. We conclude with an outline of the current government policy on the treatment of high-risk offenders with personality disorder.
\end{abstract}

\section{LEARNING OBJECTIVES}

- Know the current diagnostic criteria and epidemiology of antisocial personality disorder.

- Evaluate the evidence that antisocial personality disorder can be conceptualised as a disorder of attachment, and use a developmental framework to inform treatment interventions.

- Gain an understanding of psychological approaches to antisocial personality disorder.

\section{DECLARATION OF INTEREST}

None.

The National Institute for Health and Care Excellence (NICE) guidelines for antisocial personality disorder (National Institute for Health and Clinical Excellence 2009) were welcomed for drawing attention to this relatively common but debilitating and costly condition that until recently many psychiatrists believed was untreatable. In the past decade, the historical antipathy of psychiatrists and other mental health professionals in treating personality disorder has been effectively challenged by the publication of influential documents such as Personality Disorder: No Longer a Diagnosis of Exclusion (Department of Health 2003), the development of specific psychological therapies and the subsequent proliferation of dedicated mental health services nationally. However, the focus has been on developing effective treatments for patients with borderline personality disorder, and there remains a lack of service provision for individuals with a diagnosis of antisocial personality disorder, particularly those in the community whose behaviour is not assessed as dangerous enough or who lack a concurrent severe mental illness (usually psychosis) to meet criteria for referral to forensic mental health services.

Individuals with antisocial personality disorder often present to primary care in midlife with anxiety or depression, and may be considered for treatment in secondary mental health services. However, when their history of violence and aggressive behaviour is uncovered, health professionals often, understandably, become less willing to offer treatment owing to concerns regarding risk - particularly if no acute mental illness is identified - and professionals themselves risk being criticised for failing to adequately treat such individuals if they reoffend. Treatment providers may become further demoralised by patients' chaotic lifestyles, frequent substance misuse and the difficulties in engaging them in any treatment offered.

This pessimistic picture has been challenged, however, by emerging research into the aetiology of antisocial and aggressive behaviour that suggests that antisocial personality disorder may be conceptualised as a developmental disorder in which early attachment experiences are critical. These findings are important in designing early interventions for high-risk families and children with conduct disorder which may prevent the development of antisocial disorder in adulthood, as well as informing approaches to the management and treatment of individuals who already have the disorder.

In this article, we focus on the difficulties and challenges posed by the latter group, highlighting 
the current diagnostic confusion, lack of research determining effective treatment, and the paucity of available services for adults with antisocial personality disorder. We will review the evidence that for some individuals the disorder may be the outcome of early attachment difficulties, and informed by this developmental perspective, we will recommend a treatment framework. We conclude with a summary of the current government strategy on the management of offenders with personality disorder and new service developments involving both the National Health Service (NHS) and the criminal justice system.

\section{Diagnostic considerations}

\section{Diagnostic criteria}

In DSM-5, antisocial personality disorder is classified under Cluster B personality disorders, together with borderline, histrionic and narcissistic personality disorders (American Psychiatric Association 2013). Central features include irresponsible and antisocial behaviour, impulsivity, aggressiveness and a tendency to disregard rights and boundaries of others. ICD10 (World Health Organization 1992) defines a conceptually similar disorder to antisocial personality disorder in dissocial personality disorder, although there is more emphasis on the interpersonal deficits of the disorder than in the DSM-5 criteria and a history of conduct disorder is not necessary to make the diagnosis.

\section{Relationship with psychopathy}

Confusion exists regarding definitions of psychopathy and its relationship with antisocial personality disorder. The term psychopathy continues to be loosely applied within mental health, and is excluded from both the current ICD and DSM classifications of dissocial and antisocial personality disorder respectively. In the UK, until recently, a person could be detained in hospital against their will under the legal category of 'psychopathic disorder' within the Mental Health Act 1983, for 'a persistent disorder or disability of mind (whether or not including significant impairment of intelligence) which results in abnormally aggressive or seriously irresponsible conduct'. It was generally accepted that the term psychopathic disorder did not represent a single clinical disorder, but was a legal category describing a number of severe personality disorders, which contributed to the person committing antisocial acts. However, the reform of the Mental Health Act in 2007 has replaced all previous separate definitions of disorder, including the term psychopathic disorder, with a single category of 'mental disorder' applied throughout the Act.

In recent years, use of the term psychopathy increasingly refers to antisocial and behavioural personality traits as measured by the Hare Psychopathy Checklist - Revised (PCL-R; Hare 2003). Hare empirically validated Cleckley's seminal clinical description of a 'psychopath' (Cleckley 1941), to produce a reliable and validated operationalised risk assessment instrument consisting of a 20 -item questionnaire that is now widely used in the assessment and management of violent patients in forensic psychiatric services, and to a lesser extent in the management of violent offenders within the criminal justice system. High scores are empirically associated with a considerable increase in the likelihood of violent recidivism (Hare 1991). Hare psychopathy is not synonymous with a behavioural history of criminality or a categorical diagnosis of antisocial personality disorder, although it is often a correlate of both in severe cases.

\section{Ethical considerations}

The DSM criteria for antisocial personality disorder have been criticised for their focus on antisocial behaviour and criminality rather than on underlying personality structure and interpersonal deficits (Widiger 1993). Defining a syndrome largely by behaviours considered unacceptable by society poses ethical challenges for medical diagnosis. There has been considerable debate historically and currently about whether antisocial personality disorder, psychopathic disorder or psychopathy constitute medical conditions at all when the main symptoms are social rule-breaking and the 'patient' does not seem to suffer (McGauley 2007). Tensions between legal and medical approaches persist over whether such individuals should be punished for their behaviours rather than treated, and whether 'treatment' is really a disguise for moral re-education, particularly for people who are not voluntarily seeking help themselves.

\section{Epidemiology and service usage}

\section{Epidemiology}

Antisocial personality disorder is a common condition, with the general population prevalence in men ranging from 1\% (Torgerson 2001; Coid 2006) to $6 \%$ (Robins 1991). Studies in the UK report a prevalence of between $2 \%$ and $3 \%$ in the general population (Moran 1999; Coid 2006). Prevalence rates are consistently higher in men compared 
with women (Dolan 2009) and the disorder becomes increasingly common in mental health services, the judicial system and prison settings, representing up to $80 \%$ of the prison population (Singleton 1998; Moran 1999; Ogloff 2006).

\section{Comorbidity}

Antisocial personality disorder is associated with considerable and complex comorbidity with other mental disorders (Swanson 1994), particularly substance misuse (Robins 1991; Compton 2005). At least half of individuals with antisocial personality disorder have a co-occurring anxiety disorder (Goodwin 2003) and a quarter have a depressive disorder (Lenzenweger 2007). It is important to diagnose comorbid conditions, as the presence of antisocial personality disorder acts as a negative moderator of treatment response when these conditions are treated by conventional approaches.

\section{Costs of antisocial personality disorder}

Antisocial personality disorder is also associated with increased mortality, particularly at a young age, largely because of reckless behaviour (Black 1996). As well as causing considerable harm to the individual, people with the disorder have a broad impact on family, relationships and social functioning, and make heavy demands on the judicial system, Social Services and mental healthcare. The costs of those individuals who engage in criminal behaviour may include direct emotional and physical injury to victims, damage to property, police time, involvement with the criminal justice system, increased use of healthcare facilities, lost employment opportunities, family disruption, relationship breakdown, child-care proceedings, gambling, and problems related to alcohol and substance misuse (Myers 1998; Department of Health 1999; National Research Council 1999; National Institute for Health and Clinical Excellence 2009).

Yet, despite recognition of its high prevalence and level of psychiatric morbidity, there is evidence that people with antisocial personality disorder continue to be rejected from services because there remains a fundamental reluctance among psychiatrists to conceptualise the disorder as an illness requiring treatment. Crawford et al (2009) found that $50 \%$ of a sample of patients with antisocial personality disorder presented to emergency medical services and $21 \%$ were admitted to a mental health in-patient unit. Despite this, only $21 \%$ of the overall sample were provided with follow-up care from mental health services. However, levels of alcohol and drug misuse were significantly lower among those that were given follow-up, suggesting that general psychiatric support can be useful, although this may have been a self-selected group. Perhaps not unreasonably, given the scarcity of evidence for effective interventions for the disorder as well as the difficulties in engaging individuals, mental health services find it difficult to see a role in the management and treatment of this condition.

\section{Evidence base for effective treatments}

\section{Historical treatment studies}

Early attempts to treat antisocial personality disorder and psychopathic disorder in the UK took place largely in high secure hospitals. As with the treatment of personality disorder more generally, psychoanalytic approaches to treatment were most prevalent and led to the development of therapeutic communities (Jones 1952) in which the environmental setting itself became an essential therapeutic tool.

\section{Current treatment approaches}

More recently, in the absence of convincing evidence to justify the high costs of running such highly specialised residential treatments, the therapeutic community approach has waned in popularity and has been largely replaced by specific cognitive-behavioural therapy (CBT) programmes for offenders with personality disorder delivered within criminal justice settings. Much of the rationale for the use of these cognitive-behavioural approaches is based on the criminological literature on interventions that reduce offending behaviour. Programmes found to have the largest effect size adhere to the Risk-Need-Responsivity (RNR) model (Andrews 1995; Simon 1998), focusing on targeting patients at greatest risk of reoffending (risk), empirically established dynamic criminogenic risk factors such as criminal attitudes, substance misuse and impulsivity (need), and delivering interventions in a manner that maximises offender engagement in the treatment process (responsivity). However, it is not clear from the criminological literature how many participants in the studies considered would fulfil the diagnosis of antisocial personality disorder, and outcome criteria are usually restricted to the presence or absence of reoffending (National Institute for Health and Clinical Excellence 2009).

\section{Evidence base for psychological therapies}

Despite the proliferation of treatment programmes for offenders, only a few high-quality trials of specific psychological therapies have been conducted among people with antisocial personality disorder. 
A number of meta-analyses have highlighted the limited evidence base for effective treatments for this patient group (Warren 2003; Duggan 2007; National Institute for Health and Clinical Excellence 2009; Gibbon 2010) and reflect not only the difficulties in engaging patients in treatment studies, but also diagnostic inconsistencies and the failure of many outcome studies to distinguish between patients with and without psychopathy (De Brito 2009). A comparative evaluation of available studies is further hampered by differences in defining and measuring outcome and a focus on treating incarcerated patients rather than those in the community.

These methodological limitations were highlighted in a Cochrane review of all prospective randomised controlled trials for individuals with antisocial personality disorder (Gibbon 2010) (Box 1). However, because of the relatively robust clinical evidence indicating that groupbased cognitive and behavioural interventions are moderately effective for offenders, the NICE guidelines concluded that because this population has such a high incidence of antisocial personality disorder, it would be reasonable to conclude that such interventions were likely to be effective for people with antisocial personality disorder, and

\section{B0X 1 Cochrane review of antisocial personality disorder}

- Identified 11 prospective randomised controlled trials involving 471 individuals with antisocial personality disorder

- Only two studies focused solely on antisocial personality disorder sample

- Eleven different psychological interventions examined

- Only two studies reported on reconviction, only one on aggression

- Few studies addressed primary outcomes of aggression, reconviction, global functioning, social functioning or adverse effects

- Only three interventions were effective compared with the control groups for at least one outcome, but each intervention was originally developed for substance misuse

- Significant improvements confined to outcomes related to substance misuse

- No study reported change in any antisocial behaviour

- Insufficient trial evidence to justify any psychological intervention for adults with antisocial personality disorder

(Gibbon 2010) therefore recommend their use (National Institute for Health and Clinical Excellence 2009).

\section{Pharmacological treatment}

Evidence for pharmacological treatment of antisocial personality disorder is equally limited. Two large meta-analyses (National Institute for Health and Clinical Excellence 2009; Khalifa 2010) concluded that there was no consistent evidence that supported the use of any pharmacological intervention to treat the disorder. Pharmacological interventions should not be routinely used for treating the primary traits of antisocial personality disorder or associated behaviours of aggression, anger and impulsivity, but should only be used for the treatment of comorbid mental disorders (National Institute for Health and Clinical Excellence 2009). Issues of treatment adherence and the risks of misuse or overdose are emphasised.

\section{Aetiological and diagnostic confusion}

\section{Biological and genetic factors}

As with most psychiatric conditions, the aetiology of antisocial personality disorder is considered to have both a biological and a psychosocial foundation. In recent years there has been much interest in the genetic contribution to antisocial behaviour, particularly in children showing callous and unemotional traits, thought to be the precursors of psychopathy in adulthood. Aggressive and antisocial behaviour in such children shows a strong heritability compared with children with antisocial behaviour but an absence of callous and unemotional traits (Viding 2005), suggesting that such behaviour is 'hard-wired' into the brain from an early age. However, sophisticated adoption studies demonstrate significant gene-environment interactions. They show that children who are genetically vulnerable to behaving in an antisocial manner are likely to also experience harsh and inconsistent parenting, resulting in more pathology than would be expected from either genetic or adverse environmental influence acting alone or in combination (Cadoret 1995).

Many studies have shown differences in physiological responses and brain structure in people who are aggressive and violent compared with those who are not, including different electroencephalogram activity, reduced levels of brain serotonin (Cocarro 1996a, 1996b; Dolan 2001), and dysfunction in frontocortical and limbic brain areas (Raine 2000; Blair 2006). However, although it is important to understand the biology of aggression, the data are limited in that the studies have mostly been carried out on individuals with aggressive behaviour 
rather than those with antisocial personality disorder, and also fail to control for confounding factors such as comorbidity and substance misuse, as well as focusing on simple neurophysiological processes such as motor impulsivity or recognition of basic emotions rather than on more complex behaviour (National Institute for Health and Clinical Excellence 2009).

\section{Antisocial personality disorder and psychopathy}

The DSM-5 antisocial personality disorder category covers a heterogeneous population and does not distinguish between individuals with mild, moderate or severe psychopathy, as measured on the PCL-R. A substantial body of research has shown that, at most, only one out of three patients with antisocial personality disorder has severe psychopathy, and this latter group has a significantly poorer treatment prognosis than do patients with mild to moderately psychopathic antisocial personality disorder (Hare 1991, 2003) (Box 2). There is evidence to show that these different subgroups have different aetiological and developmental pathways and show different responses to treatment.

De Brito \& Hodgins (2009) emphasise the importance of co-occuring anxiety in identifying subgroups within antisocial personality disorder. On the basis of studies of children and adults, De Brito \& Hodgins propose that around half of the antisocial personality disorder population are characterised by anxiety as well as persistent antisocial behaviour, have low levels of callousunemotional traits as children and low levels of psychopathic traits as adults. This group is more likely to have experienced physical abuse as children and resort to violence as a compensatory response to underlying emotional conflict and distress. The other half of the population have normal to low levels of anxiety and varying levels of psychopathy, but include a subgroup with high

BOX 2 Antisocial personality disorder and psychopathy

- ICD-10 and DSM-5 describe constellations of behaviours that may be the outcome of different aetiological pathways

- Psychopathy and antisocial personality disorder are not synonymous

- Assess psychopathy independently as a separate dimension

- Higher psychopathy scores predict poorer response to treatment levels of psychopathy. This group shows high levels of callous-unemotional traits as children, low levels of anxiety, more predatory violence and are less amenable to treatment. Thus, the measurement of psychopathy is important to delineate subgroups of individuals with antisocial personality disorder who have lower psychopathy scores and higher levels of anxiety, and who may show a better response to treatment (Hodgins 2007, 2010; Ulrich 2010).

Other environmental aetiological factors implicated in antisocial personality disorder include malnutrition, smoking in pregnancy, and harsh parenting practices including parental abuse (Caspi 2002). These development risk factors for adult antisocial personality disorder are also risk factors for early attachment difficulties, which may represent a common pathway for some forms of the disorder.

\section{Attachment, mentalisation and antisocial personality disorder}

\section{Attachment studies}

Empirical evidence to support the hypothesis that antisocial personality disorder is a developmental disorder rooted in attachment comes from studies showing abnormal attachment patterns in forensic patients and prisoners diagnosed with the disorder. Several studies have shown higher levels of insecure attachment in violent offenders than in the normal population (van IJzendoorn 1997; Frodi 2001; Adshead 2004; Levinson 2004; Bogaerts 2005). This evidence is supported by studies which show that offenders in prison or secure forensic institutions are more likely to report having experienced separations, abuse and neglect from their early caregivers than the general population (Coid 1992; Heads 1997; Weeks 1998).

Although these studies do not prove a causal link between early attachment difficulties and the later development of antisocial personality disorder, the primacy of genetic and constitutional factors in the development of psychopathy is being challenged by emerging evidence that links callous and unemotional traits and psychopathic tendencies in children with disorganised attachment relationships (Pasalich 2012), maladaptive interactive patterns in families (Dadds 2012) and severe institutional deprivation (Sonuga-Barke 2010).

\section{Mentalisation deficits}

Bateman \& Fonagy (2008) propose that a substantial group of patients who fulfil diagnostic criteria for antisocial personality disorder have 
experienced significant trauma and disruptions to their attachment system in childhood, which has interfered with their neurobiological development and the development of psychological defences. This compromises their capacity to mentalise and lowers their threshold for emotional reactivity.

Mentalisation is the capacity to reflect and to think about mental states, including thoughts, beliefs, desires and affects, to be able to distinguish one's own mental states from others, and to be able to interpret the actions and behaviour of oneself and others as meaningful and based on intentional mental states (Allen 2008). Secure attachment in childhood is associated with the development of enhanced mentalisation processes, which in turn contribute to the homeostatic regulation of negative affect and arousal regulation (Schore 1996, 2001; Sarkar 2006). Children who experience significant childhood abuse, neglect or domestic violence, however, will be unable to feel safe about what others think of them, which may lead to a poorly developed capacity to mentalise, deficits in empathy, and a difficulty in distinguishing one's own mental states from others'.

\section{Violence and mentalisation}

Violent offenders may be divided into a highaffect, impulsive and hyperaroused group, and a low-affect, unemotional and psychopathic group (Meloy 2006; Adshead 2013). The first group are more likely to become violent in response to perceived threats to their sense of self. Bateman $\&$ Fonagy (2008) propose that such reactive or affective violence arises where there is a failure or inhibition of the capacity for mentalisation. A person with a limited capacity to mentalise is unable to tolerate negative emotions such as anger, hatred and a wish to hurt others, but instead may become highly aroused and overwhelmed with negative affects. For the person with antisocial personality disorder who is often particularly sensitive to threats to their self-worth or 'respect', shame and humiliation are particularly difficult emotional states to bear, and may be experienced as threatening their very psychic survival (Gilligan 2002). These unbearable feelings cannot be managed by representational means within their mind, but are experienced very concretely as feelings that need to be expelled through violence. The expression of aggression is further potentiated by the reduced capacity of the individual to mentalise - if they are unable to see others as having mental states different from theirs, this will reduce the inhibition of their aggression and violence towards others as they are unable to empathise or appreciate another person's suffering.
Mentalisation therefore protects against violence, and individuals whose capacity for mentalisation is reduced are more likely to be violent.

\section{Treatment planning}

\section{Assessment}

Treatment planning starts with a careful clinical assessment, including identification of comorbid treatable conditions such as depression or substance misuse, and assessment of key personality traits which indicate a positive response to treatment and prognosis, particularly some capacity for attachment and ability to form relationships, experience of anxiety and willingness to seek help (Box 3). Careful risk assessment, with particular attention to the patient's history of violence, should be conducted, ideally with the use of validated instruments such as the Historical Clinical Risk20 (HCR-20; Webster 1997) or the Violence Risk Appraisal Guide (VRAG; Harris 1993). The severity of psychopathy is determined with the PCL-R. Caution should be administered before considering treatment for individuals scoring highly (above 30) on the PCL-R. Meloy $(1988,2010)$ recommends that therapy will be of no benefit and should not be offered to patients with psychopathy who manifest any of the following features:

- sadistic, aggressive behaviour resulting in serious injury

- complete absence of remorse or justification for such behaviour

- very superior or mildly intellectually disabled intelligence

- a historical absence of capacity to form emotional attachments

- unexpected 'atavistic' fear felt by the experienced clinician in the patient's presence.

BOX 3 Principles of treatment planning for antisocial personality disorder

- Treatment should begin only if it is demonstrably safe and effective for both the patient and the clinician

- Careful diagnostic assessment including determining the severity of psychopathy and a clinical focus on the presence of anxiety, bonding and conscience

- Identification of any treatable conditions, such as Axis I mental or substance use disorders

- Identification of situational and environmental factors that may be aggravating or worsening the antisocial behaviours

- Careful attention to countertransference reactions (Meloy 2014) 


\section{Creating a safe setting}

An essential component of management is the setting in which treatment is delivered, wherein containment, risk, boundaries and disclosure of information are paramount (Meloy 2010). The treatment setting, whether it be a high-, mediumor low-security in-patient setting, prison or the community, must be secure enough to ensure the safety of both patients and staff before treatment planning can begin.

An attachment perspective highlights the relational aspects of the treatment setting and how the patient's early history of attachment difficulties will influence their response to care. Individuals with antisocial personality disorder are less likely to engage in help and seek treatment, and when treatment is offered they often reject it. This dismissing stance towards relationships and attacking and/or neglectful relationship to care (Ruszczynski 2010) may be conceptualised as reenactments of earlier experiences of abusive or neglectful caregivers and consequent disruptions of childhood attachment. Such challenging behaviour, however, may provoke powerful negative emotional responses in clinicians and other professionals. If unrecognised, these may lead to problematic reactions and behaviours in staff such as high staff turnover and 'burnout', avoidance of patient contact, boundary violations, pathological team and institutional dynamics, and passive-aggressive or punitive attitudes towards patients such as denying leave or overestimation of a patient's risk.

Risk can only be managed safely if the anxieties of patients, individual staff and the institutions in which they work are adequately contained (Yakeley 2010). Underlying anxiety that may trigger aggressive and antisocial acts in patients is often unrecognised, but equally, the anxieties of the staff induced by managing such patients are also frequently unacknowledged or denied. Managing negative affects in staff is a critical component of relational security, which includes recognition and analysis of the powerful countertransference reactions that these patients may provoke in those involved in their care (Box 4). Supervision and reflective practice are essential in helping staff think about how they are affected, both consciously and unconsciously, by the patients with whom they work.

\section{Specific treatment approaches}

Several specific therapies have been developed and applied in recent years for the treatment of offenders with personality disorder, including CBT
(Davidson 2009), dialectical behaviour therapy (Linehan 1993), schema-focused therapy (Chakhssi 2010) and mentalisation-based therapy (Bateman 2011). Although our own experience stems from a mentalisation-based model that we have adapted and applied to the treatment of violent men with antisocial personality disorder in an out-patient setting, we will attempt here to delineate some common features that arise during treatment and that are important to consider whatever the specific treatment modality.

\section{Mode of treatment}

The mode in which therapy is delivered can be viewed in itself as a vehicle for psychic change. The therapeutic mode can be individual, group or family therapy, or the therapeutic community itself, using its distinctive culture as a therapeutic tool. Group therapy has particular advantages for individuals with poor impulse and affect control because it is less arousing than individual therapy, and also offers more opportunities to understand other peoples' minds (Bateman 2004). Other group processes are also important, such as modelling of more appropriate behaviour and interpersonal interactions.

\section{Engagement}

Engaging and maintaining the person in treatment is a key challenge. The majority of individuals do not accept that they have mental health difficulties and will not willingly present for help. Treatment non-completion is also a significant problem, with up to $75 \%$ of offenders with personality disorder who initially engage in treatment failing to complete the course (McCarthy 2010). Treatment non-completers show poorer clinical outcomes

BOX 4 Common countertransference reactions to patients with antisocial personality disorder

- Therapeutic nihilism

- Illusory treatment alliance

- Fear of assault or harm

- Denial and deception

- Helplessness and guilt

- Devaluation and loss of professional identity

- Hatred and the wish to destroy

- Assumption of psychological complexity

- Fascination and sexual attraction

(Meloy 2014) 
than do treatment completers, as well as having significant financial cost implications for services and lowering staff morale (McMurran 2012).

Referrals for treatment may be prompted by professionals who are more concerned about reducing risk of future violent or antisocial behaviours than effecting improvements in the person's mental health or intrapsychic change. Although many programmes for offenders in secure mental health institutions or prison require the person to volunteer for treatment, motivation is often overestimated. Offenders who appear compliant and motivated in residential programmes may revert to impulsive and risky behaviours once released into the community. Moreover, it is questionable as to whether medical services should be providing an intervention whose primary aim is to reduce reoffending. Therapy should be aimed at addressing mental health and psychological factors, such as anxiety or paranoia, that contribute to the violent behaviour, rather than the latter being the sole focus of treatment.

Therapists treating patients in the community should anticipate numerous challenges, including lateness or failure to attend appointments and therapy sessions, frequent crises, boundaries violations, and drug and alcohol misuse. To minimise attrition and non-adherence to treatment, careful pre-treatment preparation is recommended. A variety of strategies may be useful, including psychoeducation about personality disorder, goalbased motivational interviews, instilling beliefs about capability for change, and implementing strategies to modulate known factors likely to reduce adherence, such as substance misuse, self-harm or a chaotic life-style (Dowsett 2008; McMurran 2012). Proactive follow-up of patients, such as calling to remind them of appointments and positively reinforcing their engagement in therapeutic tasks, will also increase adherence.

Many individuals may need an extended period of engagement or motivational work, which may occur in unconventional settings (such as the individual's hostel) and in the absence of a comprehensive assessment. Even if such psychological management does not lead to engagement in formal treatment, it may be therapeutically effective in itself.

Building a therapeutic rapport and collaborative relationship with the patient is essential. The treatment relationship should be characterised by caring, fairness and trust, and an authoritative, but not authoritarian, style. Interventions that are punitive or that focus on control and surveillance may increase risk of recidivism if not combined with rehabilitative efforts (Skeem 2009).

\section{Establishing a group process}

Whatever the treatment model, the initial task in group therapy is to establish a group process for patients whose long-standing interpersonal difficulties, suspicion and lack of trust will inevitably enter into their relationships with others in the group. This calls for active intervention on the part of the therapists in fostering links between the discourses of individual patients, who initially tend to show little interest in each other. A common tendency is for group members to drift into discussions about the problems of society where people will always take advantage of others. Although this may represent an attempt to form a common bond within a paranoid view of the world, it also marks a shift into a mode of thinking which may defend against talking about more difficult emotive topics.

\section{Linking actions to affects and internal mental states}

An important component of many psychological therapies for personality disorder is to link the patient's damaging behaviours to their internal mental states and affective experiences. However, individuals often find it very difficult to reflect on their mental states or to link their violent and antisocial behaviour with their thoughts, feelings and emotions. Asking them an apparently simple question such as 'What were you feeling before you attacked him?' can make them feel stupid and humiliated. Such individuals display a narcissistic fragility and hypersensitivity to being criticised, corrected or even interrupted, and anger may be easily activated when a patient is attempting to describe an emotive topic. Such threats to the patient's self-esteem (being 'disrespected') are important to identify, as these may expose unbearable feelings of shame that are frequently the trigger for violent behaviour. If the patient becomes too aroused, attention may be temporarily deflected away from them until they calm down by asking the other patients what they think, the therapists reflecting themselves on the situation or, if the patient appears very angry or distressed, by changing the subject altogether until the group's reflective capacity can be regained.

Because individuals with antisocial personality disorder find it very difficult to empathise with other people's affective states, interventions aimed at consideration of their effects on others, or 'victim empathy', are likely to be counterproductive and should be avoided in the early stages of treatment. Instead, interventions focusing on improving selfregard and promoting social and interpersonal 
success may contribute to creating a positive and hopeful atmosphere in the group (Bateman 2011).

\section{Boundaries}

Individuals with antisocial personality disorder experience relationships in terms of power and control, and issues of dominance and hierarchy will inevitably pervade the therapy. Rules and boundaries, which are important in any treatment, are a central feature in group therapy. Based on their own early attachment experiences of maltreatment they have a distrust of parental figures and authority and will rebel against whatever rules are imposed, including those of the group, but may have their own strict code of conduct. Boundary violations are therefore to be anticipated.

Therapists must be prepared to tolerate some expression of anti-authoritarian attitudes, acting as parental figures against which the patients can rebel, until such attitudes can be safely explored and understood within the group. A culture of trust, openness and honesty may be nurtured in the context of attachment relationships with the other group members by first helping the patients explore their own code of conduct and interactions with others within and outside of the group, and identifying the affects and states of mind that lead to violence. Developing a sense of responsibility and awareness of appropriate boundaries in relation to others is an important task of treatment, although this may be difficult in patients who have grown up in a criminal subculture.

\section{Breaks in therapy}

Breaks in treatment are particularly difficult times for these patients and are associated with an increased risk of 'acting out'. The potential impact of the therapist's absence may be underestimated due to the erratic attendance of the patients themselves and their denial of attachment needs. It is important not to collude with the patient's conscious rejection of their need for treatment, and be alert to patients becoming more disturbed during breaks in treatment, which they may find difficult to acknowledge. Similarly, difficult feelings regarding the ending of therapy should be anticipated and discussed if possible to avert premature drop-out.

\section{Gender}

We propose that male and female patients should be treated separately, and that specific services should be developed for women. This is because women present with a somewhat different diagnostic and needs profile to men, showing a higher incidence of comorbid borderline personality disorder and associated self-harm, as well as complex issues regarding pregnancy and care of their children, with the frequent involvement of Social Services and the family courts. Furthermore, our experience is that mixed groups of men and women may expose negative male attitudes towards women, which can be disruptive and contribute to poor engagement and outcomes among female patients.

\section{New directions}

Although political interest in offenders with antisocial personality disorder/psychopathy is primarily concerned with public protection, recognition of the necessity of attending to offenders' mental health, and personality disorder in particular, has gained ground in recent years.

Although beset with controversies from the start, the Dangerous and Severe Personality Disorder (DSPD) initiative in the UK (Department of Health 1999) was at least an attempt to treat, rather than solely punish, high-risk offenders. However, the programme has been criticised on a number of fronts, including: the implementation of different treatments and research methodologies with little consistency or coordination; 'warehousing' (the deliberate placement of offenders in a DSPD programme, knowing that there will be little active treatment given); patients spending little of their time in direct therapeutic activities; inadequate staffing levels; long waits for treatments; no segregation of sex offenders; the inconsistent application of discipline; and overall poor cost-effectiveness (Tyrer 2010). Despite substantial investment into research and evaluation, measurable improvements in outcomes for specific DSPD treatments and service environments were lacking, and the key question of which treatments are effective for highrisk offenders with personality disorder remains unanswered (Völlm 2012).

The DSPD programme has recently been disbanded in favour of a reconfigured national strategy for managing high-risk offenders with personality disorder based on a 'whole-systems pathway' across the criminal justice system and the NHS (Joseph 2012) (Box 5). This strategy is informed by a developmental model of personality disorder and recognition of the centrality of attachment experiences in the historical and current lives of offenders. It promotes education of the workforce about personality disorder through initiatives such as the Knowledge and Understanding Framework (www.personalitydisorderkuf.org.uk) towards the goal of creating more therapeutic environments in prisons and forensic institutions, as well as prioritising the development of specialised services 
BOX 5 Principles of the Personality Disorder Offender Pathway

- Offenders with personality disorder are managed as a shared responsibility of the National Offender Management Service and the National Health Service (NHS)

- Planning and delivery is based on a 'whole-systems' approach across the criminal justice system and the NHS, recognising the various stages of an offender's journey, from charge, conviction and prison to postrelease supervision and resettlement

- Offenders with personality disorder are primarily managed through the criminal justice system, with the lead role held by offender managers (formerly known as probation officers)

- The pathway and treatment is psychologically informed and led by psychologically trained staff; it focuses on relationships and the social context in which people live

- Outcomes from related programmes for young people and families are incorporated into the offender pathway to contribute to breaking the intergenerational cycle of crime

- In developing services, account is taken of the experiences and perceptions of offenders and staff at the different stages of the pathway

(Joseph 2012)

for the management and treatment of neglected groups of offenders with personality disorder, including women, adolescents and young adults, and those with intellectual disabilities. The importance of meaningful patient involvement in the development and delivery of services is also emphasised.

However, these initiatives - and other service developments for people with antisocial personality disorder that are much needed, particularly in the community - can only be sustained in the long run if interventions are developed and empirically shown to be effective through highquality randomised controlled trials, despite the considerable methodological challenges in conducting research with this patient group. This may be facilitated by more collaborative research between proponents of specific psychological therapies for personality disorder and elucidation of common mutative mechanisms, as well as identifying specific therapeutic techniques and strategies for individuals with this particularly exigent disorder. This would also help to refine the development and delivery of effective, psychologically informed management strategies, as we recognise that formal treatment may only be appropriate or available for a minority of individuals.

We suggest that making psychological approaches more available for people with antisocial personality disorder will contribute to a reduction not only in their offending and the distress they cause others, but also in the distress and disturbance that they themselves experience and which underlies their antisocial behaviour.

\section{References}

Adshead G (2004) Three degrees of security: attachment in forensic institutions. In A Matter of Security: The Application of Attachment Theory to Forensic Psychiatry and Psychotherapy (eds F Pfafflin, G Adshead): 147-66. Jessica Kingsley Publishers.

Adshead G, Moore E, Humphrey M, et al (2013) The role of mentalising in the mangemnt of violence. Advances in Psychiatric Treatment, 19: 67-76.

Allen JG, Fonagy P, Bateman A (2008) Mentalizing in Clinical Practice. American Psychiatric Press.

American Psychiatric Association (2013) Diagnostic and Statistical Manual of Mental Disorders, Fifth Edition (DSM-5). APA.

Andrews D (1995) The psychology of criminal conduct and effective treatment. In What Works: Reducing Reoffending. Guidelines from Research and Practice (ed. J McGuire): 3-34. Wiley \& Sons.

Bateman A, Fonagy P (2004) Psychotherapy for Borderline Personality Disorder: Mentalisation-Based Treatment. Oxford University Press.

Bateman A, Fonagy P (2008) Co-morbid antisocial and borderline personality disorders: mentalisation-based treatment. Journal of Clinical Psychology: In Session, 64: 181-94.

Bateman AW, Fonagy P (2011) Antisocial personality disorder. In Handbook of Mentalizing in Mental Health Practice (eds AW Bateman, $\mathrm{P}$ Fonagy): 289-308. American Psychiatric Publishing.

Black DW, Baumgard CH, Bell SE, et al (1996) Death rates in 71 men with antisocial personality disorder. A comparison with general population mortality. Psychosomatics, 37: 131-6.

Blair RJR, Peschardt KS, Budhani S, et al (2006) The development of psychopathy. Journal of Child Psychology and Psychiatry and Allied Disciplines, 47: 262-75.

Bogaerts S, Vanheule S, Declerq F (2005) Recalled parental bonding, adult attachment style and personality disorders in child molesters: a comparative study. Journal of Forensic Psychiatry and Psychology, 16: 445-58.

Cadoret RJ, Yates WR, Troughton E, et al (1995) Genetic-environmental interaction in the genesis of aggressivity and conduct disorders. Archives of General Psychiatry, 52: 916-24.

Caspi A, McClay J, Moffitt TE, et al (2002) Role of genotype in the cycle of violence in maltreated children. Science, 297: 851-4.

Chakhssi F, de Ruiter C, Bernstein D (2010) Change during forensic treatment in psychopathic versus nonpsychopathic offenders. Journal of Forensic Psychiatry and Psychology, 21: 660-82.

Cleckley H (1941) The Mask of Sanity. Mosby.

Coccaro EF, Kavoussi RJ, Sheline Yl, et al (1996a) Impulsive aggression in personality disorder correlates with tritiated paroxetine binding in the platelet. Archives of General Psychiatry, 53: 531-6.

Coccaro EF, Berman ME, Kavoussi RJ, et al (1996b) Relationship of prolactin response to d-fenfluramine to behavioral and questionnaire assessments of aggression in personality-disordered men. Biological Psychiatry, 40: 157-64.

Coid J (1992) DSM-III diagnosis in criminal psychopaths: a way forward. Criminal Behaviour and Mental Health, 2: 78-94.

Coid J, Yang M, Tyrer P, et al (2006) Prevalence and correlates of personality disorder in Great Britain. British Journal of Psychiatry, 188: 423-31. 


\section{MCO answers \\ $\begin{array}{lllll}1 \mathrm{~b} & 2 \mathrm{c} & 3 \mathrm{~d} & 4 \mathrm{e} & 5 \mathrm{a}\end{array}$}

Compton WM, Conway KP, Stinson FS, et al (2005) Prevalence, correlates, and comorbidity of DSM-IV antisocial personality syndromes and alcohol and specific drug use disorders in the United States: results from the national epidemiologic survey on alcohol and related conditions. Journal of Clinical Psychiatry, 66: 677-85.

Crawford MJ, Sahib L, Bratton H, et al (2009) Service provision for men with antisocial personality disorder who make contact with mental health services. Personality and Mental Health, 3: 165-71.

Dadds MR, Allen JL, Oliver BR, et al (2012) Love, eye contact and the developmental origins of empathy $v$. psychopathy. British Journal of Psychiatry, 200: 191-6.

Davidson KM, Tyrer P, Tata P, et al (2009) Cognitive behaviour therapy for violent men with antisocial personality disorder in the community: an exploratory randomised controlled trial. Psychological Medicine, 39: 569-77.

De Brito SA, Hodgins S (2009) Antisocial personality disorder. In Personality, Personality Disorder and Violence (eds M McMurran, R Howard): 133-53. Wiley.

Department of Health (2003) Personality Disorder: No Longer a Diagnosis of Exclusion. Department of Health.

Department of Health, Home Office (1999) Managing Dangerous People with Severe Personality Disorder: Proposals for Policy Development. Home Office and Department of Health.

Dolan M, Anderson IM, Deakin JFW (2001) Relationship between 5-HT function and impulsivity and aggression in male offenders with personality disorders. British Journal of Psychiatry, 178: 352-9.

Dolan M, Vollm B (2009) Antisocial personality disorder and psychopathy in women: a literature review on the reliability and validity of assessment instruments. International Journal of Law and Psychiatry, 32: 2-9.

Dowsett J, Craissati J (2008) Managing Personality Disordered Offenders in the Community: A Psychological Approach. Routledge.

Duggan C, Adams C, Ferriter M, et al (2007) The use of psychological treatments for people with personality disorder: a systematic review of randomised controlled trials. Personality and Mental Health, 1: 95-125.

Frodi A, Dernevik M, Sepa A, et al (2001) Current attachment representations of incarcerated offenders varying in degree of psychopathy. Attachment and Human Development, 3: 269-83.

Gibbon S, Duggan C, Stoffers J, et al (2010) Psychological interventions for antisocial personality disorder. Cochrane Database of Systematic Reviews, 6: CD007668.

Gilligan J (2002) Violence: Our Deadliest Epidemic and its Causes. Jessica Kingsley Publishers.

Goodwin RD, Hamilton SP (2003) Lifetime comorbidity of antisocial personality disorder and anxiety disorders among adults in the community. Psychiatry Research, 117: 159-66.

Hare R (1991) The Hare Psychopathy Checklist - Revised Manual. MultiHealth Systems.

Hare R (2003) Hare Psychopathy Checklist - Revised (PCL-R) (2nd edn). Multi-Health Systems.

Harris GT, Rice ME, Quinsey VL (1993) Violent recidivism of mentally disordered offenders: the development of a statistical prediction instrument. Criminal Justice and Behavior, 20: 315-35.

Heads T, Taylor P, Leese M (1997) Childhood experiences of patients with schizophrenia and a history of violence: a special hospital sample. Criminal Behaviour and Mental Health, 7: 117-30.

Hodgins S (2007) Persistent violent offending: what do we know? British Journal of Psychiatry, 49 (suppl 49): s12-4.

Hodgins S, de Brito A, Chhabra P, et al (2010) Anxiety disorders among offenders with antisocial personality disorders: a distinct subtype? Revue Canadienne de Psychiatrie, 55: 784-91.

Jones M (1952) A Study of Therapeutic Communities. Tavistock.

Joseph N, Benefield N (2012) A joint offender personality disorder pathway strategy: An outline summary. Criminal Behaviour and Mental Health, 22: 210-17.
Khalifa N, Duggan C, Stoffers J, et al (2010) Pharmacological interventions for antisocial personality disorder. Cochrane Database of Systematic Reviews, 8: CD007667.

Lenzenweger MF, Lane MC, Loranger AW, et al (2007) DSM-IV personality disorders in the National Comorbidity Survey Replication. Biological Psychiatry, 62: 553-64

Levinson A, Fonagy $\mathrm{P}$ (2004) Offending and attachment: the relationship between interpersonal awareness and offending in a prison population with psychiatric disorder. Canadian Journal of Psychoanalysis, 12: 225-51

Linehan MM (1993) Cognitive-Behavioural Treatment of Borderline Personality Disorder. Guilford Press.

McCarthy L, Duggan C (2010) Engagement in a medium secure personality disorder service: a comparative study of psychological functioning and offending outcomes. Criminal Behaviour and Mental Health, 20: 112-28.

McGauley G, Adshead G, Sarkar S (2007) Psychotherapy of psychopathic disorders. In The International Handbook of Psychopathic Disorders and the Law: Diagnosis and Treatment, Vol 1 (eds A Felthouse, H Sass): 449-66. John Wiley \& Sons.

McMurran M (2012) Readiness to engage in treatments for personality disorder. International Journal of Forensic Mental Health, 11: 289-98.

Meloy JR (1988) The Psychopathic Mind: Origins, Dynamics and Treatment. Jason Aronson.

Meloy JR (2006) Empirical basis and forensic application of affective and predatory violence. Australian and New Zealand Journal of Psychiatry, 36: 9-30.

Meloy JR, Yakeley J (2010) Treatment of cluster B disorders: antisocial personality disorder. In Psychodynamic Psychotherapy for Personality Disorders: A Clinical Handbook (eds J Clarkin, P Fonagy, G Gabbard): 349-78. American Psychiatric Press.

Meloy JR, Yakeley J (2014) Antisocial personality disorder. In Gabbard's Treatments of Psychiatric Disorders (eds GO Gabbard, J Gunderson). American Psychiatric Publishing (in press)

Moran P (1999) The epidemiology of antisocial personality disorder. Social Psychiatry and Psychiatric Epidemiology, 34: 231-42.

Myers MG, Stewart DG, Brown SA (1998) Progression from conduct disorder to antisocial personality disorder following treatment for adolescent substance abuse. American Journal of Psychiatry, 155: $479-85$.

National Institute for Health and Clinical Excellence (2009) Antisocial Personality Disorder: Treatment, Management and Prevention (NICE Clinical Guideline 77). NICE.

National Research Council (1999) Pathological Gambling: a Critical Review. Washington Academy Press.

Ogloff JR (2006) Psychopathy/antisocial personality disorder conundrum. Australian and New Zealand Journal of Psychiatry, 40: 519-28.

Pasalich DS, Dadds MR, Hawes DJ, et al (2012) Attachment and callousunemotional traits in children with early-onset conduct problems. Journal of Child Psychology and Psychiatry, 41: 302-13.

Raine A, Lencz T, Bihrle S, et al (2000) Reduced prefrontal gray matter volume and reduced autonomic activity in antisocial personality disorder. Archives of General Psychiatry, 57: 119-27.

Robins LN, Tipp J, Przybeck T (1991) Antisocial personality. In Psychiatric Disorders in America: The Epidemiological Catchment Area Study leds LN Robins, DA Regier): 258-90. The Free Press.

Ruszczynski S (2010) Becoming neglected: a perverse relationship to care. British Journal of Psychotherapy, 26: 22-32.

Sarkar J, Adshead G (2006) Personality disorders as disorganisation of attachment and affect regulation. Advances in Psychiatric Treatment, 12: 297-305.

Schore A (1996) Experience dependent maturation of a regulatory system in the orbital pre-frontal cortex and the origin of developmental psychopathology. Development and Psychopathology, 8: 59-87. 
Schore A (2001) The effect of early relational trauma on right brain development, affect regulation and infant mental health. Infant Mental Health Journal, 22: 201-49.

Simon LMJ (1998) Does criminal offender treatment work? Applied Preventive Psychology, 7: 137-59.

Singleton N, Melzer H, Gatward R, et al (1998) Psychiatric Morbidity Among Prisoners in England and Wales. HMSO.

Skeem J, Polaschek D, Manchak S (2009) Appropriate treatment works but how? Rehabilitating general, psychopathic, and high risk offenders. In Psychological Science in the Courtroom: Consensus and Controversies (eds JL Skeem, KS Douglas, SL Lilienfeld): 358-84. Guilford.

Sonuga-Barke EJ, Schlotz W, Kreppner J (2010) Differentiating developmental trajectories for conduct, emotion and peer problems following early deprivation. Monographs of the Society for Research in Child Development, 75: 102-24.

Swanson MC, Bland RC, Newman SC (1994) Epidemiology of psychiatric disorders in Edmonton. Antisocial personality disorders. Acta Psychiatrica Scandinavica Supplementum, 376: 63-70.

Torgerson S, Kringlen E, Cramer V (2001) The prevalence of personality disorders in a community sample. Archives of General Psychiatry, 58 : 590-6.

Tyrer P, Duggan C, Cooper S, et al (2010) The successes and failures of the DSPD experiment: the assessment and management of severe personality disorder. Medicine, Science and the Law, 50: 95-9.

Ulrich S, Coid J (2010) Antisocial personality disorder - stable and unstable subtypes. Journal of Personality Disorders, 24: 171-87. van IJzendoorn MH, Feldbrugge JT, Derks FC, et al (1997) Attachment representations of personality-disordered criminal offenders. American Journal of Orthopsychiatry, 3: 449-59.

Viding E, Blair RJ, Moffitt TE, et al (2005) Evidence for substantial genetic risk for psychopathy in 7-year-olds. Journal of Child Psychology and Psychiatry and Allied Disciplines, 46: 592-7.

Völlm B, Konappa N (2012) The dangerous and severe personality disorder experiment: review of empirical research. Criminal Behaviour and Mental Health, 22: 165-80.

Warren F, McGauley G, Norton K, et al (2003) Review of Treatment for Severe Personality Disorder. Home Office Report 30/03. Home Office.

Webster CD, Douglas KS, Eaves D, et al (1997) HCR-20: Assessing Risk for Violence, Version 2. Mental Health, Law and Policy Institute, Simon Fraser University.

Weeks R, Widom CS (1998) Self-report of early childhood victimization among incarcerated adult male felons. Journal of Interpersonal Violence, 13: $346-61$.

Widiger TA, Corbitt EM (1993) Antisocial personality disorder: proposals for DSM-IV. Journal of Personality Disorders, 7: 63-77.

World Health Organization (1992) The ICD-10 Classification of Mental and Behavioural Disorders: Clinical Descriptions and Diagnostic Guidelines. WHO

Yakeley J (2010) Working with Violence - A Contemporary Psychoanalytic Approach. Palgrave Macmillan.

\section{MCQs}

Select the single best option for each question stem

1 At least half of individuals diagnosed with antisocial personality disorder:

a have high psychopathy scores on the PCL-R

b have co-occuring anxiety disorder

c have comorbid depressive disorder

$\mathrm{d}$ are admitted to a mental health in-patient unit following presentation to an accident and emergency department

e engage in treatment offered

\section{Regarding treatment for antisocial} personality disorder:

a low-dose antipsychotics are recommended for impulsivity

b therapeutic communities have been shown to be the most effective treatment

c cognitive-behavioural treatments have the best evidence base $\mathrm{d}$ treatment is best delivered within forensic services

e programmes found to have the largest effect size focus on risk.

3 Psychopathy:

$\mathrm{a}$ is synonymous with antisocial personality disorder

$\mathrm{b}$ is untreatable

c is a separate category in DSM- 5

d may be associated with a history of severe institutional deprivation

e is most accurately measured by the HCR- 20 .

4 In the development of antisocial personality disorder:

a early-onset antisocial behaviour in childhood often becomes attenuated in adulthood

b callous-unemotional traits are genetically determined c children with antisocial behaviour and high levels of anxiety are more likely to engage in predatory violence if they develop antisocial personality disorder in adulthood

$\mathrm{d}$ studies show that the majority of violent offenders with antisocial personality disorder show insecure attachment patterns

e insecure attachment predisposes to deficits in mentalisation.

5 The most effective psychological treatments for antisocial personality disorder:

a focus on linking affects to actions

b prioritise countertransference

c take place in a physically secure treatment setting

d involve individual therapy

e enforce strict rules and boundaries. 